\title{
TIMING OF REMOVAL OF SUTURES IN CONTROL OF POST-OPERATIVE ASTIGMATISM
}

\author{
M. R. STANFORD, T. FENECH and P. A. HUNTER \\ London
}

\begin{abstract}
SUMMARY
A prospective, randomised study was carried out in $\mathbf{1 3 5}$ patients to determine whether the time of removal of continuous sutures in the relief of post-operative astigmatism had any effect on subsequent changes in cylinder power or axis. After uncomplicated extracapsular cataract extraction with a corneal section and continuous 10/0 nylon suture, patients with more than 3 dioptres of cylinder were allocated to have their suture removed at 6,9 or 12 weeks post-operatively. Visual and optical outcome were assessed 1 week after suture removal and at 6 months. Although the time of removal did not affect the change in cylindrical power, the subsequent refraction was more stable when the suture was removed at 12 weeks. However, initial against-the-rule astigmatism did not significantly change after suture removal and resulted in an unsatisfactory final prescription. Suture removal should therefore be performed at 12 weeks, glasses should not be prescribed early, and a poor outcome may be anticipated in those initially against-the-rule.
\end{abstract}

Modern cataract surgery with current microsurgical techniques is a safe and effective procedure. One of the major causes of visual morbidity following surgery is the occurrence of surgically induced astigmatism which may result in reduced visual acuity, off-axis blur, monocular diplopia, and spectacle intolerance. ${ }^{1}$ Two main factors contribute to the pathogenesis of this complication: the section and the suture. Various studies have emphasised the importance of the length of the section, ${ }^{2}$ its distance from the limbus, ${ }^{3}$ the prevention of sideways shift in the wound ${ }^{4}$ the number of sutures used ${ }^{5.6}$ and their type ${ }^{7-9}$ and variations in the suturing technique. ${ }^{10.11}$ However, more important than these is the amount of tension in the suture, a loose or absorbable suture tending to cause wound gape and thus horizontal flattening of the cornea

From: Department of Ophthalmology, King's College Hospital, London SE5, UK.

Correspondence to: Mr. M. R. Stanford, FCOphth, Medical Eye Unit, St Thomas' Hospital, London SE1 7EH, UK. (against-the-rule astigmatism), and a tight or non-absorbable suture causing wound compression and vertical stretching of the cornea (with-the-rule astigmatism). ${ }^{12-15}$

Despite the considerable literature on how to avoid, correct or reduce post-operative astigmatism, the question of the most appropriate time to remove sutures has only been addressed anecdotally. ${ }^{16,17}$ In cases with a high degree of cylinder a balance must be sought between early removal when one might expect the greatest resolution of cylinder but corneal wound healing may not be complete, especially if the patient is still on topical steroids, and late removal where wound healing is complete which may carry the risk of a permanent high cylinder. We therefore undertook a prospective, randomised study to investigate whether removal of sutures at different times post-operatively would affect the change in cylindrical power or axis, and what effect this might have on visual and optical outcome at 6 months.

\section{PATIENTS AND METHODS}

Patients entered into this study were drawn prospectively from those attending the Eye Department, King's College Hospital. In all cases patients had undergone routine extracapsular cataract extraction by a variety of surgeons with a $120^{\circ}$ corneal incision $1 \mathrm{~mm}$ anterior to the limbus, lens expression and aspiration, posterior chamber intraocular lens insertion (Sinskey type), and closure of the section with a continuous $10 / 0$ nylon bootlace suture. Post-operatively patients received steroid drops (gutt dexamethasone $0.1 \%$ ) four times a day, the dosage being gradually reduced after 2 weeks. At 6 weeks, if more than 3 dioptres of cylinder were present, patients were randomly allocated to one of three groups after the nature of the procedure had been explained and consent obtained. Patients excluded from this study were those under the age of 50 , those in whom the pre-operative refraction was more than 3 dioptres (determined, where refraction was not possible, by keratometry or from their most recent glasses), those in whom peri- or post-operative complications (vitreous loss, wound leak) had occurred, and those in whom pre- 


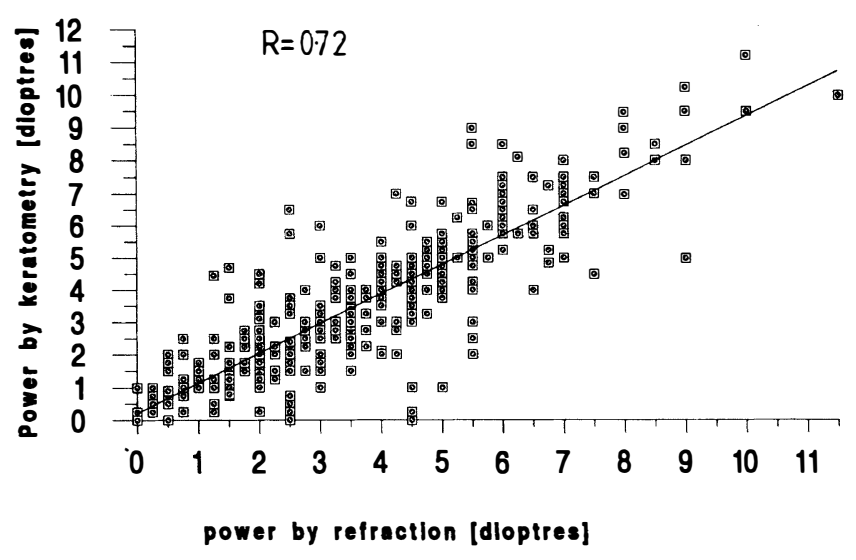

Fig. 1. Scattergram representing correlation of degrees of astigmatism as measured by keratometry and refraction $(p<0.001)$.

vious surgery or corneal irregularities prevented accurate refraction and keratometry.

In the study group suture removal was performed at either 6 weeks (group A), 9 weeks (group B) or 12 weeks (group C) post-operatively. The study was also stratified by subdividing each group into those patients who had 3-5 dioptres of cylinder and those with more than 5 dioptres. The cylindrical power and axis were determined objectively at each visit by refraction and keratometry (Bausch and Lomb). Suture removal was performed under local anaesthetic with local antibiotic cover given for 5 days afterwards. One week after suture removal the refraction was again determined and glasses prescribed. Each patient was reassessed 6 months post-operatively when the vision, refraction, and reasons for reduced vision $(6 / 9$ or worse) were determined. For the purposes of this study with-the-rule astigmatism is defined as that which is corrected by a plus cylinder at $90^{\circ} \pm 30^{\circ}$ and against-the-rule astigmatism as that which is corrected by a plus cylinder at $180^{\circ} \pm 30^{\circ}$, the remaining $60^{\circ}$ representing oblique astigmatism. $^{18}$

Results were analysed within and between separate groups with respect to with-the-rule or against-the-rule astigmatism, change in cylindrical power and axis, age and sex by the Mann-Whitney test. Where appropriate $2 \times$ 2 contingency tables were contructed and chi-squared analysis used. A value of $p<0.05$ was considered significant.

Table I. Patients' age, sex and cylindrical power at 6 weeks post-operatively

\begin{tabular}{lcccc}
\hline & Group A & Group B & Group C & Total \\
\hline $\begin{array}{l}\text { Cylindrical power } \\
\quad \text { (dioptres) }\end{array}$ & & & & \\
$3-5$ & 20 & 28 & 25 & 73 \\
$>5$ & 19 & 25 & 18 & 62 \\
Sex & & & & \\
Male & 12 & 21 & 14 & 47 \\
Female & 27 & 32 & 29 & 88 \\
Age (years) & & & & \\
$50-70$ & 15 & 18 & 14 & 47 \\
$>70$ & 24 & 35 & 29 & 88 \\
\hline
\end{tabular}

Table II. Type of astigmatism present in each group at 6 weeks

\begin{tabular}{lcrrrrrrr}
\hline & \multicolumn{2}{l}{ With-the-rule } & \multicolumn{2}{c}{ Against-the-rule } & \multicolumn{2}{c}{ Oblique } & \multirow{2}{*}{ Total } \\
\cline { 2 - 3 } & $3-5$ & $>5$ & $3-5$ & $>5$ & $3-5$ & $>5$ & \\
\hline Group A & 10 & 9 & 5 & 6 & 5 & 4 & 39 \\
Group B & 11 & 16 & 13 & 4 & 4 & 5 & 53 \\
Group C & 11 & 13 & 11 & 3 & 3 & 2 & 43 \\
Total & $70(55 \%)$ & $42(33 \%)$ & $23(12 \%)$ & 135 \\
\hline
\end{tabular}

\section{RESULTS}

One hundred and thirty-six patients were recruited into the study. Data on 135 patients (Table I) were available for analysis 1 week after suture removal and data on 126 at 6 months. One patient (in group A) suffered a wound dehiscence that required resuturing, having rubbed her eye some hours after suture removal, and was subsequently excluded. Nine patients' data were not available at 6 months: 3 had died and the rest failed to attend for follow-up. The degree of astigmatism as determined by refraction correspond closely with the measurements obtained by keratometry (Fig. 1, $p<0.001$ ), indicating that the observed refraction was due to changes in corneal curvature. The initial refraction performed at 6 weeks in all patients did not change significantly when performed prior to suture removal at 9 weeks (group B) and 12 weeks (group C), i.e. patients with over 5 dioptres of cylinder still had over 5 at the time of suture removal. The type of astigmatism present in each group at six weeks is shown in Table II. Overall 55\% had with-the-rule, $33 \%$ against-therule, and $12 \%$ oblique astigmatism.

\section{Changes 1 Week After Suture Removal}

The changes in the cylindrical power and axis at 1 week after suture removal are shown in Table III. The changes in patients with 3-5 dioptres of cylinder are smaller than those with $>5$ dioptres, but this was found to reach significance only for group $\mathrm{C}(p<0.05)$. Overall there was no significant difference between groups. The change in axis of astigmatism was not significantly different either within or between groups.

The change in cylindrical power when the groups are considered according to the type of astigmatism is given in Table IV. Here, the change is less in those with 3-5 dioptres than in those with $>5$ dioptres, except in group B. Patients with against-the-rule astigmatism show significantly less change than patients with other types, and this

Table III. Changes in cylindrical power and axis 1 week after suture removal

\begin{tabular}{lccc}
\hline & Group A & Group B & Group C \\
\hline $\begin{array}{l}\text { Change in cylinder } \\
\quad \text { (dioptres) }\end{array}$ & & & \\
$3-5$ & $3.1 \pm 2.3$ & $2.8 \pm 2.5$ & $2.7 \pm 2.4^{\mathrm{a}}$ \\
$>5$ & $4.6 \pm 4.1$ & $5.9 \pm 3.8$ & $5.9 \pm 2.5^{\mathrm{a}}$ \\
$\begin{array}{l}\text { Change in axis } \\
\quad \text { (degrees) }\end{array}$ & & & \\
$3-5$ & $15.2 \pm 13.4$ & $16.4 \pm 16.4$ & $14.4 \pm 12.0$ \\
$>5$ & $18.4 \pm 16.0$ & $20.6 \pm 14.0$ & $13.8 \pm 11.9$ \\
\hline $\mathrm{a}<0.05$. & & &
\end{tabular}


Table IV. Mean change in cylindrical power related to the type of astigmatism prior to suture removal

\begin{tabular}{|c|c|c|c|c|c|c|}
\hline & \multicolumn{2}{|c|}{ With-the-rule } & \multicolumn{2}{|c|}{ Against-the-rule ${ }^{a}$} & \multicolumn{2}{|c|}{ Oblique } \\
\hline & $3-5$ & $>5$ & $3-5$ & $>5$ & $3-5$ & $>5$ \\
\hline Group A & 4.45 & 8.20 & 0.05 & 0.08 & 2.15 & 3.52 \\
\hline Group B & 4.74 & 7.78 & 0.40 & 0.43 & 2.25 & 6.17 \\
\hline Group C & 3.81 & 6.32 & 0.30 & 1.50 & 3.81 & 5.16 \\
\hline
\end{tabular}

${ }^{a}$ All values in this group are significantly smaller $(p<0.001)$ than the values in corresponding groups.

was the only population in which some patients showed an actual increase in power. The change in axis also showed variation between types, the largest change being in those with oblique and the least in those with against-the-rule astigmatism. Those patients that initially showed againstthe-rule astigmatism remained against-the-rule after suture removal. However, the majority of patients (group A, $55 \%$; group B, $66 \%$, group C, $68 \%$ ) who were with-iherule became against-the-rule after suture removal.

\section{Changes Occurring at 6 months Post-operative?}

One hundred and twenty-six patients completed the stutv. The final visual acuity at 6 months was $6 / 6$ or beiter in $85 \%$; the reasons for poor visual acuity are given in Thble $\mathrm{V}$. The results for change in both cylinder and axi: are reported in terms of the patient requiring a new prescription; there had either been a change of 1 diopire or more of power, $10^{\circ}$ or more of axis, or both (Tible vI). Patients with a $>5$ dioptres of cylinder initially were more likely to need a new prescription than those witi 3-5 dioptres. Moreover patients whose sutures were removed early were significantly more likely to need a new prescription than those in whom they were removed later (group A vs. group $\mathrm{C} ; p<0.01$ )

The final refraction at 6 months was also examined in terms of whether suture removal had succeeded in reducing the patient's prescription to an acceptable level (s y linder power less than 3 dioptres). The results are shown in Table VII and demonstrate that about $20 \%$ of patients who had 3-5 dioptres initially still had an unsatisfactory prescription at 6 months, with a trend that the later the suture was removed the less likely this was to happen. Similarly, for patients with more than 3 dioptres of cylinder initially, one quarter of those in groups A and B still needed more than 3 dioptres whereas none did in group $C$. When the groups are taken together, those patients whose sutures were removed latest had the least number of unsatisfactory prescriptions. If the initial type of astigmatism is considered, equal numbers of patients required a change of prescription at 6 months (Table VIII). However, it is strik-

Table V. Reasons for poor visual acuity (6/9 or worse) at 6 months

\begin{tabular}{lc}
\hline & No. of patients \\
\hline Posterior capsule opacification & 6 \\
Diabetic maculopathy & 5 \\
Macular degeneration & 5 \\
Macula oedema & 3 \\
Total & $19(15 \%)$ \\
\hline
\end{tabular}

Table VI. Number of patients requiring a new prescription (change in cylinder power $>1$ dioptre change in axis $>10^{\circ}$, or both) at 6 months post-operatively

\begin{tabular}{|c|c|c|c|}
\hline & $3-5$ & $>5$ & Total \\
\hline Group A & $10 / 20$ & $12 / 19$ & $22 / 39^{a} \quad(56 \%)$ \\
\hline Group B & $10 / 26$ & $8 / 22$ & $19 / 48 \quad(39 \%)$ \\
\hline Group C & $5 / 24$ & $5 / 15$ & $10 / 39^{a} \quad(25 \%)$ \\
\hline Total & $25 / 50(35 \%)$ & $26 / 56(46 \%)$ & $51 / 126(40 \%)$ \\
\hline
\end{tabular}

"Differences between group $\mathrm{A}$ and group $\mathrm{C}$ significant at $p<0.01$ (chi-squared).

ing that of these patients with against-the-rule astigmatism initially, only one quarter had a satisfactory final prescription at 6 months (Table IX).

The results of analysis with respect to the patient's age and sex showed no significant difference in any parameter either 1 week after suture removal or at 6 months post-operatively.

\section{DISCUSSION}

Alteration in the shape of the cornea following cataract extraction was first noted by Donders in 1864, who reported against-the-rule astigmatism following surgery. ${ }^{19}$ Since then this change has been increasingly recognised although, with modern suture material, the change is usually with-the-rule. ${ }^{7.9 .12 .13}$ Prior to the development of intraocular lenses this was not of major concern since it could be corrected by spectacles, but with the advent of both soft contact and intraocular lenses spectacle overcorrection became necessary, the cylinder required being relatively greater than that for aphakic spectacles for the same amount of corneal astigmatism according to the principle of lens effectiveness. ${ }^{79}$ Moreover changes in the cylindrical power and axis continue for some time postoperatively, even if sutures are not removed, resulting in delayed visual rehabilitation. The causes of post-operative astigmatism are numerous ${ }^{16}$ but basically fall into two groups: those that are related to the section ${ }^{2-11}$ and those that are due to the suture. ${ }^{12-14}$ In the latter case both wound compression and wound gape have been implicated in determining outcome.

This study was designed to discover whether the time of removal of a continuous 10/0 nylon suture in a corneal section would significantly alter the change in cylindrical power that resulted. Statistical comparison between the results of refraction and keratometry demonstrated a strong correlation, indicating that the observed astigmatism was due to changes in the corneal topography rather than other structures, and this confirms the findings of

Table VII. Number of patients with an unsatisfactory prescription ( $>3$ dioptres of cylinder) at 6 months post-operatively

\begin{tabular}{lclll}
\hline & $3-5$ & $>5$ & \multicolumn{2}{c}{ Total } \\
\hline Group A & $8 / 20$ & $5 / 19^{\mathrm{a}}$ & $13 / 39^{\mathrm{b}}$ & $(28 \%)$ \\
Group B & $8 / 26$ & $4 / 22^{\mathrm{a}}$ & $12 / 48^{\mathrm{b}}$ & $(23 \%)$ \\
Group C & $3 / 24$ & $0 / 15^{\mathrm{a}}$ & $3 / 39^{\mathrm{b}}$ & $(5 \%)$ \\
Total & $19 / 70(27 \%)$ & $9 / 56(16 \%)$ & $28 / 126$ & $(22 \%)$ \\
\hline
\end{tabular}

$p<0.01$, group $\mathrm{C}$ to groups $\mathrm{A}$ and $\mathrm{B}$.

${ }^{\mathrm{b}} p<0.01$, group $\mathrm{C}$ to groups $\mathrm{A}$ and $\mathrm{B}$. 
Table VIII. Number of patients requiring change of prescription at 6 months according to initial type of astigmatism

\begin{tabular}{lcccc}
\hline & \multicolumn{3}{c}{ Against-the- } & Oblique \\
With-the-rule & rule & Total \\
\hline Group A & $12 / 19$ & $5 / 11$ & $5 / 9$ & $22 / 39$ \\
Group B & $9 / 26$ & $8 / 14$ & $2 / 8$ & $19 / 48$ \\
Group C & $5 / 22$ & $4 / 13$ & $1 / 4$ & $10 / 39$ \\
Total & $15 / 67(39 \%)$ & $17 / 38(45 \%)$ & $18 / 21(38 \%)$ & $51 / 126(40 \%)$ \\
\hline
\end{tabular}

other studies. ${ }^{79,13}$ In contrast to other series, one third of our patients exhibited against-the-rule astigmatism postoperatively. This may arise from poor technique that allows wound gape during suturing, which then leads to scar formation increasing the circumference of the globe, thus flattening the cornea in the meridian perpendicular to the section. ${ }^{20}$

The change in the cylindrical power at 1 week after suture removal was not significantly different between groups except that, as might be expected, the higher the cylinder the more the change. In all groups the change in axis was similar, although those patients in group $\mathrm{C}$ showed least (Table III). Patients who showed against-therule astigmatism all stayed against-the-rule after suture removal. This is not unexpected if one accepts that this type of astigmatism is caused by wound gape, and the fact that some of these patients got worse after suture removal reinforces this conclusion. A change from with-the-rule to against-the-rule astigmatism was seen in $50 \%$ of patients in all groups after suture removal. This is in contrast to other studies where removal of a continuous suture did not affect with-the-rule astigmatism. ${ }^{7,9,12}$ However, in those studies the suture was cut rather than removed, so that the wound was still supported to some extent, and cutting was done at 3 months or later when wound healing was more advanced. It may also be that, in groups A and B where the suture was removed early, an element of wound slippage contributed to this change.

This study, in common with others, may be criticised for the lack of a control group. Indeed there is no formal study in the literature of the natural history of post-operative suture-induced astigmatism of more than 5 dioptres. The establishment of such a control group would need to be done prospectively and might be difficult to justify since the natural history of unrelieved suture-induced astigmatism changes at the most by 1 dioptre over 1 year, ${ }^{7.13,15,21,22}$ late suture cutting (at 6 months or more) may be less effective due to advanced wound healing and some patients might require additional surgical procedures to relieve residual astigmatism, and the prolongation

Table IX. Number of patients in whom final prescription was satisfactory according to initial type of astigmatism

\begin{tabular}{lcccc}
\hline & With-the-rule & $\begin{array}{c}\text { Against-the- } \\
\text { rule }\end{array}$ & Oblique & Total \\
\hline Group A & $16 / 19$ & $4 / 11$ & $6 / 9$ & $26 / 39$ \\
Group B & $25 / 26$ & $3 / 14$ & $8 / 8$ & $36 / 48$ \\
Group C & $22 / 22$ & $10 / 13$ & $4 / 4$ & $36 / 39$ \\
Total & $63 / 67(94 \%)$ & $17 / 38^{\mathrm{a}}(44 \%)$ & $18 / 21(85 \%)$ & $98 / 126(78 \%)$ \\
\hline aP $P<0.001($ chi-squared) & & &
\end{tabular}

${ }^{\mathrm{a}} P<0.001$ (chi-squared). of a significant astigmatic error delays visual rehabilitation thus defeating the aims of surgery. ${ }^{9}$ Vector analysis to calculate the magnitude of astigmatism following suture removal has been recommended ${ }^{12,13,16}$ but was not used in this study. However, the pre-operative astigmatism was not significantly different between groups (data not shown) and, whilst this may have biased the results in patients with 3-5 dioptres of cylinder, the bias would not have extended to patients in the $>5$ dioptres group.

Analysis of results at 6 months showed that changes in cylindrical power and axis continued after glasses were prescribed, with a trend that the later the suture was removed the smaller the change that was seen (Table VI). This might reflect the fact that less time was available for any change to occur in patients in group $\mathrm{C}$, but probably indicates that wound healing is more stable at 12 weeks. The fact that $40 \%$ of our patients required a new prescription at this time strongly suggests that giving new glasses 1 week after suture removal is unwise, and it is probably better to leave this for 4 weeks to allow stabilisation of the corneal topography. ${ }^{9,10,21}$ Twenty-two per cent of our patients still had more than 3 dioptres of cylinder at 6 months (Table VII), this being least common in group C. When this figure is examined with respect to the initial type of astigmatism it becomes apparent that a highly significant majority of patients had against-the-rule astigmatism initially. Indeed only $4(6 \%)$ of those patients who initially showed with-the-rule astigmatism had more than 3 dioptres of cylinder at 6 months.

From the results of this study we would recommend that where a continuous $10 / 0$ nylon corneal suture is causing a high with-the-rule cylinder it should be removed at 12 weeks after surgery; not only is this as effective in relieving induced astigmatism as earlier removal but it is safer and the refraction is more stable thereafter. We also recommend that prescription of glasses should be left for 4 weeks after suture removal, particularly if this is done at 6 or 9 weeks. Removal of sutures in a patient with significant against-the-rule astigmatism may make matters worse and these patients tend to have an unsatisfactory optical outcome.

The authors wish to thank the consultant and junior staff of King's College Hospital for their support during this project and Mrs. D. Embleton for preparing the manuscript.

Key words: Astigmatism, Pseudophakia, Suture removal.

\section{REFERENCES}

1. Thornton SP. Cataracts and the surgical control of astigmatism. J Cataract Refract Surg 1989;15:11.

2. Reading VM. Astigmatism following cataract surgery. Br J Ophthalmol 1984;68:97-104.

3. Iliff CE, Khodadoust A. The control of astigmatism in cataract surgery. Trans Am Ophthalmol Soc 1967;65:160-7.

4. Torchia RT, McCarthy RW. The cornered incision - a precision cataract wound. Ophthalmic Surg 1983;14:72-4.

5. Singh D, Kumar K. Keratometric changes after cataract extraction. Br J Ophthalmol 1976;60:638-41.

6. Rowan PJ. Corneal astigmatism following cataract extraction. Am Ophthalmol 1978;10:231-4.

7. Stainer GA, Binder PS, Parker WT et al. The natural and 
modified course of post-cataract astigmatism. Ophthalmic Surg 1982;13:822-7.

8. Gorn RA. Surgically induced astigmatism and its spontaneous regression. Ophthalmic Surg 1985;16:162-4.

9. Kronish JW, Forster RK. Control of corneal astigmatism following cataract extraction by selective suture cutting. Arch Ophthalmol 1987;105:1650-5.

10. Thygesen J, Reersted P, Fledelius H, Corydon L. Corneal astigmatism after cataract surgery. A comparison of corneal and corneoscleral incisions. Acta Ophthalmol 1979;57: 243-50.

11. Gibson Moore J. Incidence of astigmatism after cataract surgery: comparison of continuous and interrupted sutures. Trans Ophthalmol Soc UK.1977;97:104-5.

12. Jaffe NS, Clayman HM. The pathophysiology of corneal astigmatism after cataract extraction. Ophthalmology 1975; 79:615-30.

13. Wishart MS, Wishart PK, Gregor ZJ. Corneal astigmatism following cataract extraction. Br J Ophthalmol 1986;70: 825-30.

14. Troutman RC. Control of corneal astigmatism in cataract and corneal surgery. Trans Pacific Coast Otolaryngol Ophthalmol Soc 1970;51:217-31.

15. Parker WT, Clorfeine GS. Long-term evolution of astigmatism following planned extracapsular cataract extraction. Arch Ophthalmol 1989;107:353-7.

16. Swinger CA. Post-operative astigmatism. Surg Ophthalmol 1987;31:219-47.

17. Emery J. Questions and answers: how do you time the cutting of sutures to relieve astigmatism after cataract surgery? Arch Ophthalmol 1989;107:1732.

18. Waring G. Corneal structure and pathophysiology. In: Leibowitz HM, editor. Corneal disorders. Philadelphia: Saunders, 1984:1-6.

19. Danders FC. On the anomalies of accommodation and refraction of the eye. London: New Sydenham Society, 1864:334.

20. Hyde LL, Maumenee AE. The double shoelace cross-tied suture. In: Emery J, Paton D, editors. Current concepts in cataract surgery; selected proceedings of the Fourth Biennial Cataract Surgical Congress. Philadelphia: Mosby, 1976:62. 